\title{
Exploring Business Perceptions of the Compliance Costs of Regulation
}

\author{
Phil Lewis, Alice Richardson and Michael Corliss \\ University of Canberra, Australia
}

\begin{abstract}
The compliance costs of regulation borne by businesses operating in Australia are of growing concern, particularly the disproportionate impact upon small business. This paper uses correspondence analysis on a survey of businesses in NSW and Victoria to further investigate the links between the characteristics of businesses such as firm size, difficulty with various types of regulation and external advice. The main findings of this paper are that although there is a positive relationship between firm size and difficulty complying with government regulation, the level of difficulty seems to have a minimum level even for the very small firms. Furthermore it appears that certain types of external advice, particularly advice from accountants, may operate to significantly reduce the difficulty firms have maintaining compliance.
\end{abstract}

\section{Key Words}

Regulation, Compliance cost, Firm size, Small business

\section{Introduction}

Small businesses are very important to the Australian economy. They account for over 47 percent of all employment, over 32 percent of wages and salaries, over 30 percent of sales and service income, over 42 percent of operating profit (before tax) and over 35 percent of industry value added (ABS 2012).

Costs of regulation can be conveniently divided into direct costs, allocative inefficiency and compliance costs (Lewis et al 2014). Compliance costs are the focus of this study. Compliance costs fall into three general categories. The first relates to becoming aware of regulations which must be abided by. This might involve hiring particular expertise (accountants, lawyers, for example), taking part in training or having to devote time by owners or staff in educating themselves in what exactly is required under legislation and the costs of non-compliance. The second relates to the costs of actually abiding by the regulation. For instance, health and safety regulation might prescribe the purchase of special equipment such as safety guards, helmets, wash basins, first aid kits etc. The third category of costs relates to demonstrating compliance with legislation. This mostly involves record keeping, which increasingly involves computer packages but is often referred to as paperwork. The boundary between actually complying with legislation and demonstrating compliance can be somewhat blurred. The costs include hiring outside professional help, devoting staff to compliance related activities or, quite likely for small businesses, devoting the owner's own time.

\section{Background}

Copyright (C) 2015 Victoria University. This document has been published as part of the Journal of Law and Governance in both online and print formats. Educational and non-profit institutions are granted a non-exclusive licence to utilise this document in whole or in part for personal or classroom use without fee, provided that correct attribution and citation are made and this copyright statement is reproduced. Any other usage is prohibited without the express permission of the publisher.
See Lewis et al. (2014) provide a broad overview of the regulatory landscape for small business, definitions of compliance costs and small business. Here the focus is on the costs associated with regulation that is over and above the normal day to day running cost of a business, particularly if the regulation imposes costs upon those being regulated that are unnecessary. Such costs 
have been defined by the Productivity Commission (2007) as being a regulatory burden and include terms found in the literature, which are used interchangeably, such as compliance costs, administrative costs and regulatory costs (Chittenden et al 2002).

The costs of compliance to business are considered to be substantial, although quantifying these burdens has proved difficult (Banks 2006). Conservative estimates put compliance costs to the Australian economy at tens of billions of dollars annually (Banks 2006). The costs of regulation include time, paperwork, capital outlays, and deflection from core business activities. From the submissions sent to the Productivity Commission it is estimated that compliance can take up to 25 percent of the time of senior management and boards of large companies' time (Banks 2006).

This paper concentrates on small businesses and fills a gap in the literature by providing quantification of the costs of regulation in terms of both time and money. In this paper we use a recent survey of small businesses in Australia to explore, using correspondence analysis, the perceptions of these businesses about the relationship between sources of advice and cost of compliance with Government regulation.

\section{Methodology}

In this paper we are concerned with the association between the various categorical variables of a survey of businesses regarding their views on the cost of compliance with government regulation. For example the association between the size of the firm (of which there are five size categories) and the dollars they spend meeting government compliance (of which there are five different categories of expenditure). The Developing a Responsive Regulatory System (DARRS) survey was conducted in 2010 in New South Wales and Victoria. From the survey there were 391 valid responses to various questions relating to business activity and the costs associated with being compliant with government regulation. A detailed description of the survey is provided in Lewis et al. (2014).

For this type of study correspondence analysis is well suited. Correspondence analysis is a way of analysing a two-way table of data that was developed by French statisticians, most notably Benzecri: see, for example, Benzecri (1992). The standard reference in English as a first language is Greenacre (1984). Correspondence analysis compares the relative row and column distributions of a two way table. Take for example firm size and dollars spent meeting compliance. If firm size was tabulated vertically and dollars spent horizontally, the relative row distribution would show, for example, for the firm size between 1 and 5 people what proportion of those firms spent less than $\$ 1,000$, between $\$ 1,000$ and $\$ 5,000$, between $\$ 6,000$ and $\$ 10,000$ etc. Similarly, the relative column distribution would show, for example, for the dollars spent less than $\$ 1,000$ in what proportion of those that spent less than $\$ 1,000$ were the firm size less than 1 person, between 1 and 5 people etc. Correspondence analysis then seeks to optimise the correlation between row and column scores by extracting dimensions. The first dimension contains the optimised scores and the second and subsequent dimensions maximize the correlation between row and column scores, subject to ensuring that the second and subsequent dimensions do not explain any of the variance between the categorical variables already captured in the first dimension. This constraint makes the explanatory power of all the dimensions cumulative and ensures that the first dimension is the primary dimension in which most of the variance between the categorical variables is captured.

Correspondence analysis has been used successfully in the medical sciences (Greenacre 1992), environmental sciences (Digby and Kempton 1988) as well as the social sciences (Blasius and Thiessen 2001). Greenacre and Hastie (1987) explain how to interpret three aspects of a correspondence analysis plot. Observed distances between the row points on the plot are approximate Euclidean distances weighted by the proportion of observations in each row. Thus points that are close correspond to row categories that behave in a similar way. On the other hand, observed distances between column points are not strictly distances. Points that are close correspond to column categories that behave in a similar way, but no distances can be attached to this interpretation. Finally, there is also a geometric relationship between the row and column points on the plot. Row points that 
are close to particular column points correspond to rows that are weighted heavily on those particular columns.

An extension of correspondence analysis, multiple correspondence analysis, can examine the relationship between more than two categorical variables. For a description of multiple correspondence analysis refer to Greenacare and Blasius (2006). Here we use both correspondence analysis and multiple correspondence analysis.

For the purpose of allowing greater ease with which the results can be interpreted, a detrending technique has been applied. For a number of the plots shown here the original results took a horseshoe-like formation. Digbyand Kempton (1987) note that a horseshoe shape of many correspondence analysis plots is a common feature that is a result of the method of derivation of scores. Straightening or detrending the horseshoe makes identifying the axis more straight forward. Although there are various methods for detrending, here we use polynomials to create a line that best fits the results of the correspondence and multiple correspondence analysis due to the improved accuracy noted by Ter Braak and Prentice (1988). The correspondence analysis was carried out in SAS and graphs were drawn in R (R Core Team 2014).

Applications of correspondence analysis to survey data can be found in fields as diverse as tourism (Beldona et al. 2005) and information systems (Berthon et al. 2001). BERR (2008) uses multiple correspondence analysis to visualise tables of business opinions (ranging from strongly disagree to strongly agree) and 15 core regulation questions. The correspondence analysis revealed four clusters, three of which were interpretable: regulatory environment, market environment and business operations.

\section{Results}

In the survey respondents were asked to rate the difficulty they have had with respect to a number of areas of regulation on a scale of 1 not difficult at all through to 5 most difficult. Here if a respondent rated a regulatory issue as either 4 or 5 this has been taken to mean the respondent has had difficulty maintaining compliance with this particular issue.

The results are structured as follows. A correspondence analysis is carried out on the two-way tables showing compliance difficulty for each regulation in the rows and firm characteristics (size, days spent on compliance and dollars spent on compliance) in the columns. Two dimensions were extracted. Scores for each row and column category were plotted in Figures 2 - 4. Figure 5 is then a visual summary of three firm characteristics (size, days and dollars as just described). The final results are correspondence analyses on the two-way tables showing for each regulation, source of advice in the rows and difficulty in the columns. Two dimensions were extracted. Scores for each row and column category were plotted in Figures $6-9$.

An important step when exploring further into business perceptions with compliance difficulty is to get a relative sense of which regulations entail the greatest problems. However, much of the literature relating to the cost of compliance is focused upon the burden of complying with taxation regulation or looking at individual regulation types without offering a relative sense of where the greatest issues are perceived. We would expect to see then, that for firms in our sample, taxation compliance or in this case record keeping for tax purposes to be relatively more troublesome than other types of regulation.

Figure 1 shows the percentage of firms in the sample that have had difficulty with compliance by regulation type. 
Figure 1 Compliance Difficulty by Regulation Type, percent of businesseses.

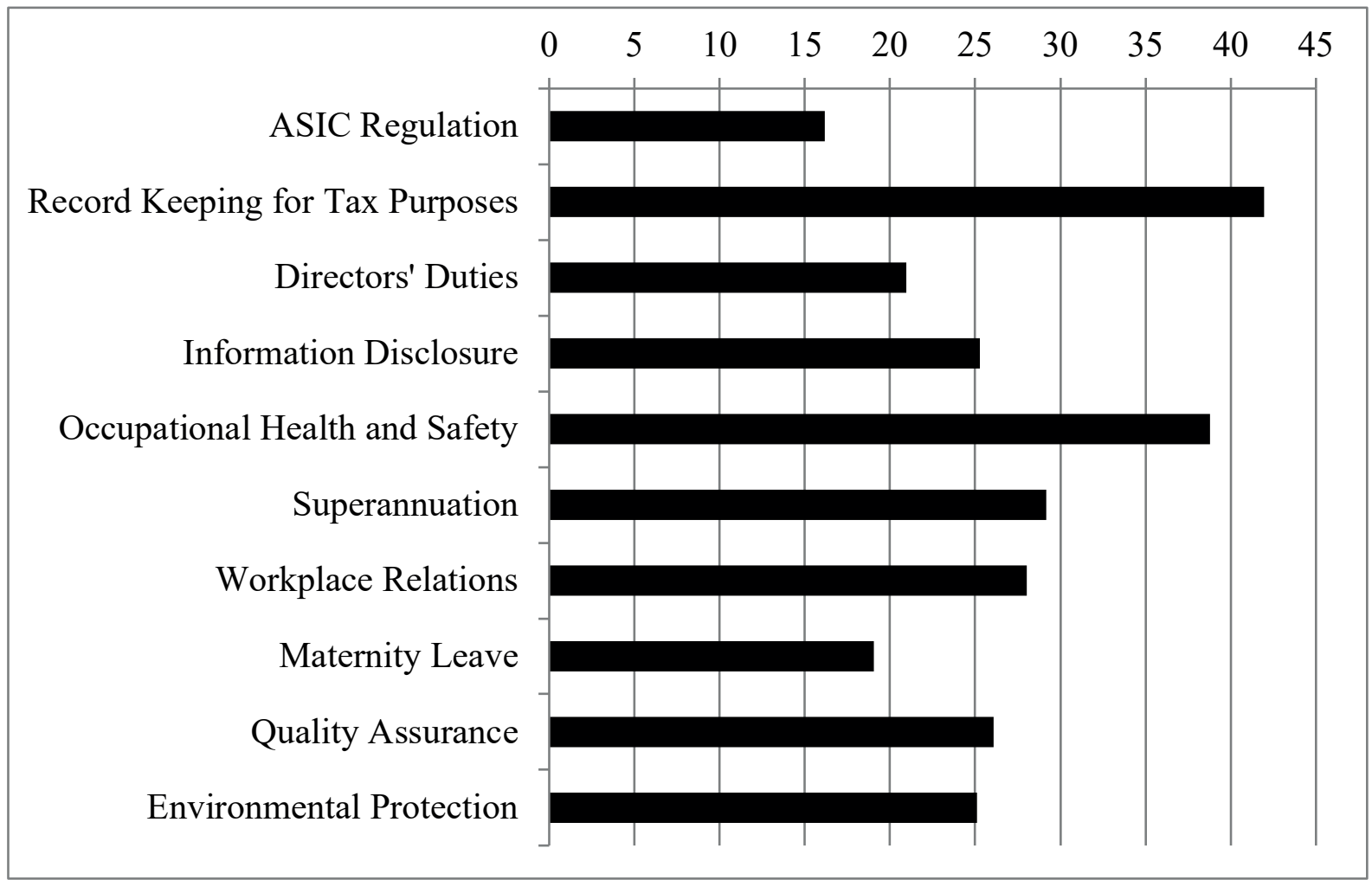

Clearly the greatest issues relate to recording keeping for tax purposes, with 42 percent of business having trouble, and occupational health and safety, with 39 percent of businesses finding it difficult to comply with. On record keeping, one respondent commented

"Taxation law and compliance [is] difficult to follow as I am not a professor on taxation law - and neither are the "helpful' folk who take calls for the Tax Office (they are all subject to changing their minds, that is not what I meant or I will have to seek someone else's advice)".

On Occupational Health and Safety $(\mathrm{OH} \& \mathrm{~S})$, another said that

"OH\&S [is] very hard to proactively determine level of satisfactory compliance ('paper trail' measurement with considerable cost/workload too often applied/relied on, and retrospectively)".

Other regulation types such as superannuation, workplace relations, information disclosure, quality assurance, environmental protection and directors' duties had a significant proportion of firms in the sample reporting difficulty with compliance. Maternity leave and ASIC regulation appears to be the least troublesome of all the regulation types with only 16 percent and 14 percent of firms within the sample reporting problems respectively. 
Figure 2 Compliance Difficulty by Cost of Compliance (\$)

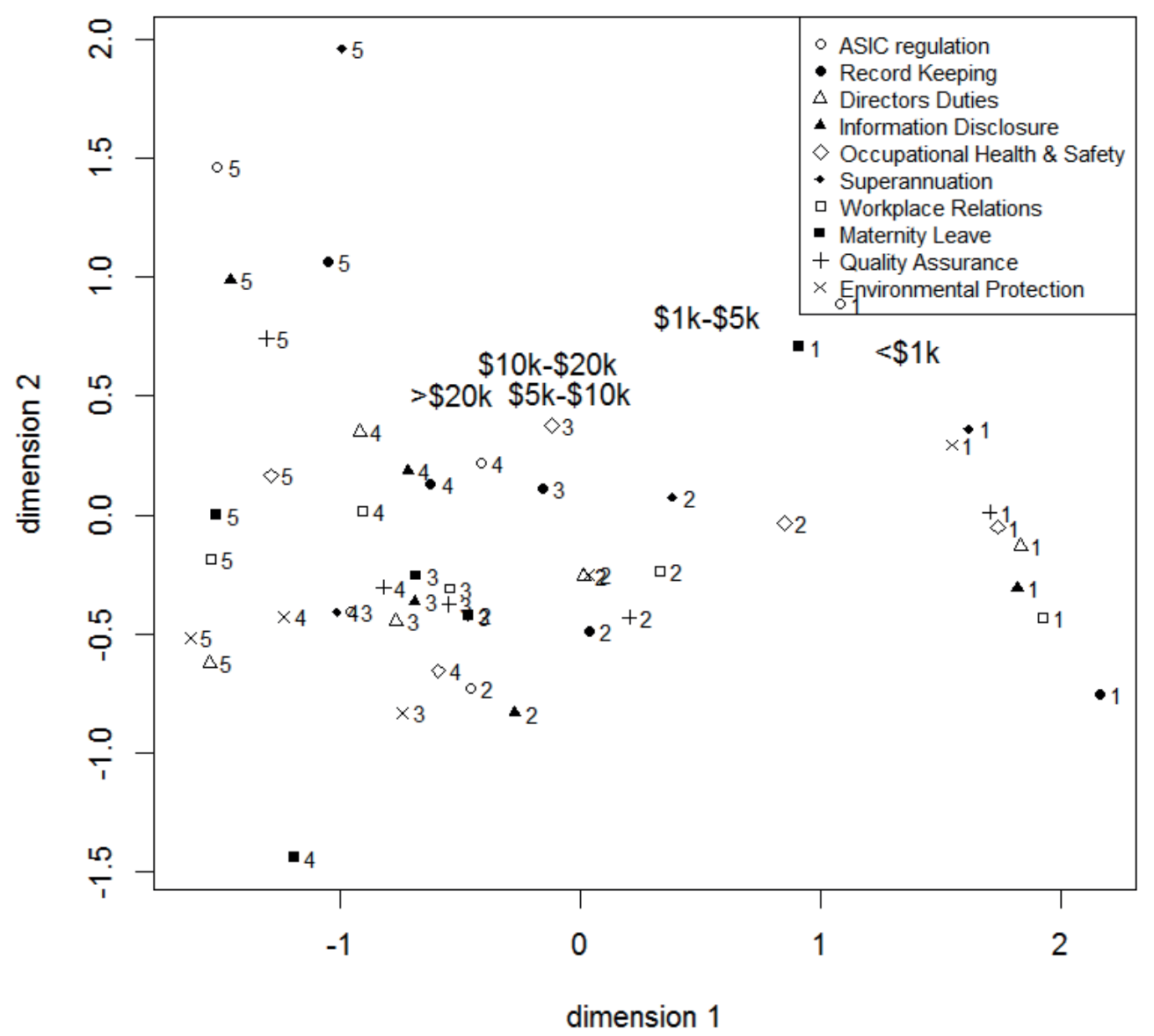

Figure 2 shows the compliance difficulty of various regulations (see legend) by cost of compliance (dollar figures on the graph with $\$ 1 \mathrm{k}=\$ 1000$ ). The questions asked in the survey of each regulation were 'how would you rate the difficulty caused by this issue (1=not difficult at all, $5=$ most difficult)' and 'how much do you spend on compliance per annum $(<\$ 1 \mathrm{k}, \$ 1 \mathrm{k}-\$ 5 \mathrm{k}, \$ 5 \mathrm{k}-\$ 10 \mathrm{k}, \$ 10 \mathrm{k}-\$ 20 \mathrm{k}$, $>\$ 20 \mathrm{k})$ ?'.

The level of difficulty decreases from left to right across the graph, as does the dollar figure. Because of the detrending technique applied here, the vertical position of points is not interpretable. The proximity of the points labelled 1 and the dollar figure $<\$ 1 \mathrm{k}$ shows that firms who don't spend much don't perceive that they have very many compliance problems. Some businesses may be using strategies to reduce costs despite difficulties - for instance the respondent who said

"I complete administration after hours (I work full time) to cut expenses of wages etc of book keepers."

Similarly, the proximity of the points labelled 4 and 5 and the dollar figure $>\$ 20 \mathrm{k}$ confirms the expected outcomes that firms who do spend a lot perceive that they find compliance very difficult. There is no clear pattern of behaviour amongst the ten regulations, as the points for each regulation are scattered fairly randomly in the plot. Comments from respondents tended to be general when relating cost to regulation, for example "the significant burden created by regulatory cost ... largely does not add value". 


\section{Figure 3 Compliance Difficulty by Cost of Compliance (Days)}

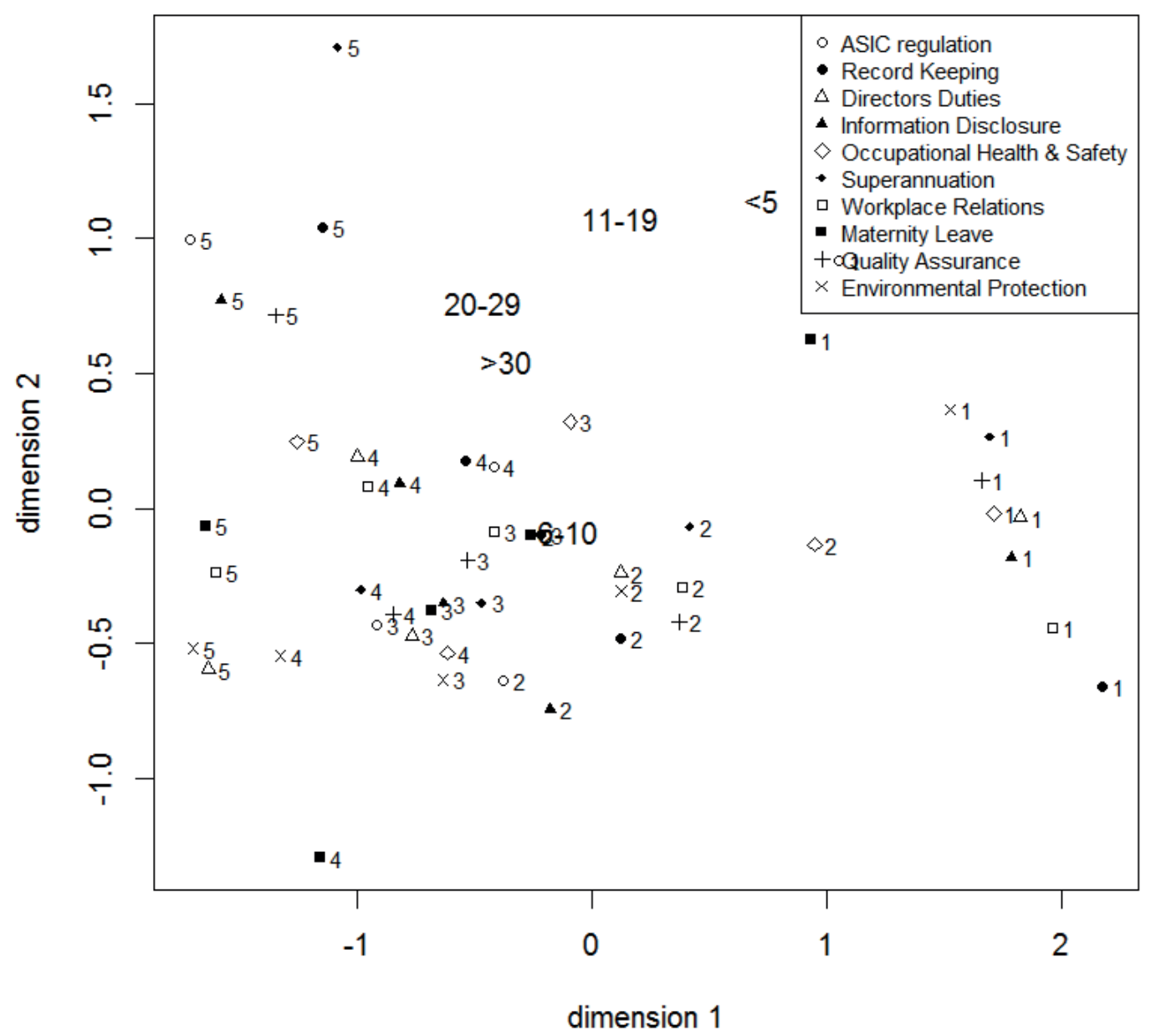

Figure 3 shows the compliance difficulty ( $1=$ not difficult at all, $5=$ most difficult) of various regulations (see legend) by cost of compliance (in days i.e. $<5,6-10,11-19,20-29,>30$ ).

The level of difficulty decreases from left to right across the graph. The days tend to decrease as well, but the pattern is not as strong as the dollar figure; it is probably easier for businesses owners to know or guess dollar amounts than time amounts. The proximity of the points labelled 1 and the days $<5$ shows that firms who don't spend much time don't perceive that they have very many compliance problems. Similarly, the proximity of the points labelled 4 and 5 and the 20-29 and $>30$ days confirms the expected outcomes that firms who do spend a lot of time perceive that they find compliance very difficult. There is no clear pattern of behaviour among the ten regulations, as the points for each regulation are scattered fairly randomly in the plot.

Only two regulation types were mentioned by respondents, one who said that

"Reporting for Occupational Health and Safety is extremely onerous and time consuming"

and another who said that

"Taxes cost for ... staff time". 
Figure 4 Type of Compliance Difficulty by Firm Size

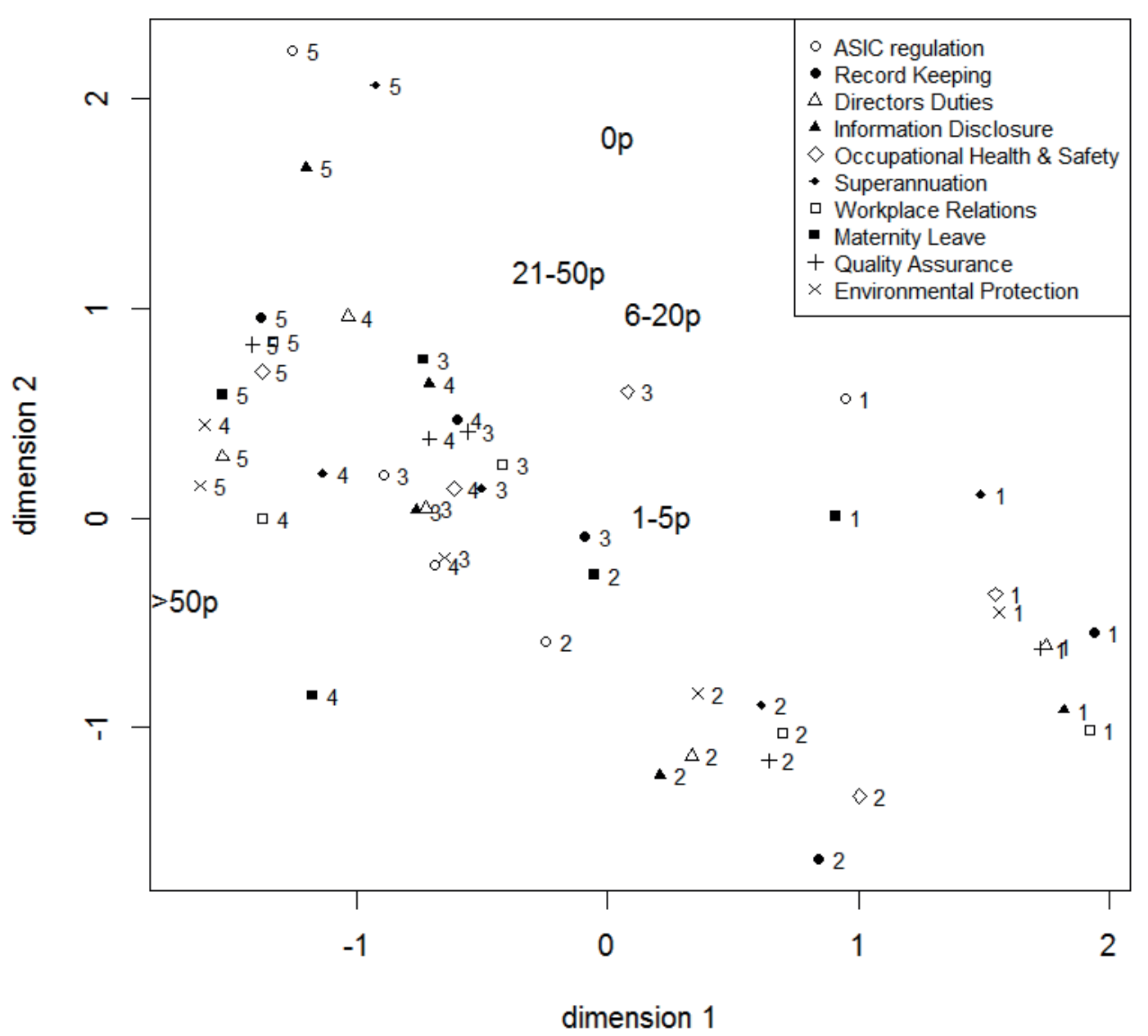

Another area of the literature dealing with the cost of compliance relates to the size of the firm. Overwhelming evidence suggests that there is a disproportionate burden upon smaller businesses. One might expect smaller firms to have less regulation to comply with given much of the regulation deals with employees such as superannuation or workplace relations etc. On the other hand, small businesses do not have the advantage of economies of scale in administration that larger firms have. 
Figure 5: Cost of compliance (days and dollars) by firm size

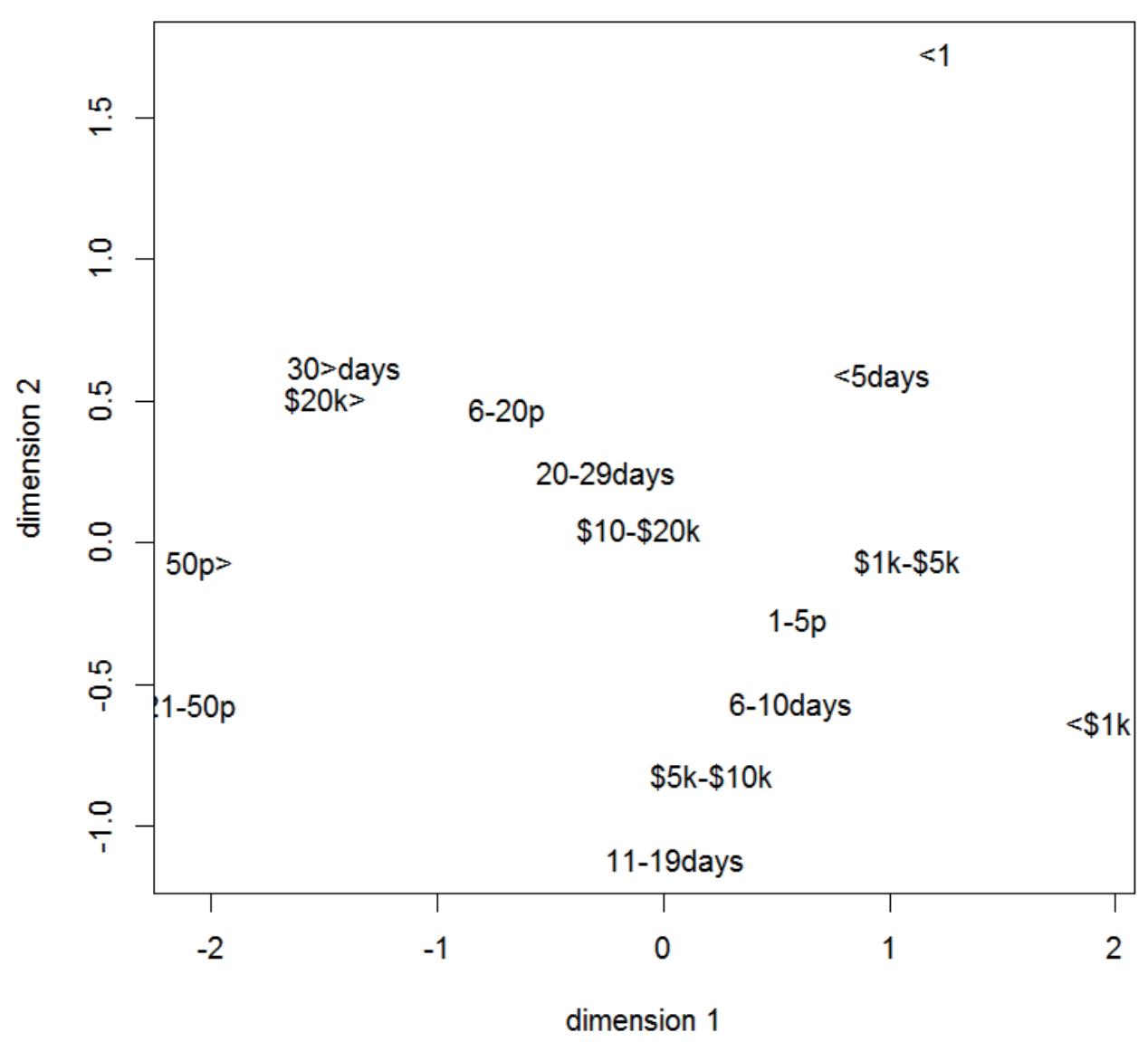

Figure 5 shows the cost of compliance (in days i.e. $<5,6-10,11-19,20-29,>30$ and dollars i.e. $(<\$ 1 \mathrm{k}$, $\$ 1 \mathrm{k}-\$ 5 \mathrm{k}, \$ 5 \mathrm{k}-\$ 10 \mathrm{k}, \$ 10 \mathrm{k}-\$ 20 \mathrm{k},>\$ 20 \mathrm{k})$ by firm size $(<1,1-5,6-20,21-50,>50$ employees).

The size of the firm overall (in terms of days, dollars and employees) decreases from left to right across the graph. The proximity of the points labelled $>30$ days, $>50$ employees and $>\$ 20 \mathrm{k}$ suggests that larger firms spend more on compliance in time as well as money. Similarly, the proximity of the points labelled 20-29 days, 10-\$20k and 6-20 employees suggests that middle-sized forms spend a middle-sized amount on compliance. The interesting spread around time and money for the smallest firms suggests that there is much more variation in the way small firms spend time and money on compliance. However, generally it appears to show evidence of a disproportionate burden of compliance upon small businesses. It seems there is little difference in the level of difficulty complying with government regulation for firm sizes up to and including 21 to 50 people. For firm sizes over and above 50 people, however, the difficulty increases considerably.

For some, small firm size is an advantage:

"Being a very small business we do not have a lot of the regulatory issues which major companies may encounter."

But not all would agree: 
"A one man band ensuring everything complies."

Some respondents mentioned the shift of certain regulatory responsibility from government to business, and noted that being small increases the impact of this trend. Three regulations were mentioned by respondents:

"Tax - government using small business to collect tax for them \& not reimbursed for this";

"Maternity leave is yet another service that government is getting small business to do on their behalf";

and

"Occupational health \& safety regulations that are not workable in small businesses ..."

\section{Sources of Advice}

One tool that businesses use to assist them with understanding government regulation is external advice. The Small Business Deregulation Task Force (1996) found that, on average, of the total costs incurred by small businesses keeping compliant nearly half went on external advice. It may be of interest then to investigate which type of advice is associated with easing the burden of compliance. Additionally it could also be interesting to investigate if firms perceive government advice to be useful or not. Given the discussion in the literature relating to the burden of taxation compliance and the results previously shown in Figure 1, which pointed to record keeping for tax purposes being the greatest issue for businesses, we would expect to see accountants making the greatest positive impact. If a type of advice is effective at easing the burden of compliance we might expect to see higher levels of expenditure on advice associated with lower levels of compliance difficulty for the various types of regulation. Although these figures only show the association between various categorical variables, it would be most unusual, although not implausible, for greater advice expenditure to cause greater compliance difficulty. Therefore we might assume, on average, that the direction of causation is from compliance difficulty to advice expenditure.

Our survey looked at four types of advice which included advice from industry, lawyers, accountants, and government. The question asked in the survey for each type of advice was 'what is the proportion of your expenditure on each source of advice?' and 'how would you rate the difficulty caused by the following issues ( $1=$ not difficult at all, $5=$ most difficult). The following four figures look at the association between these various types of advice and the difficulty complying with various types of government regulation.

Figure 6 shows the association between the cost of compliance and expenditure on industry advice. 
Figure 6 Compliance Difficulty by Industry Advice

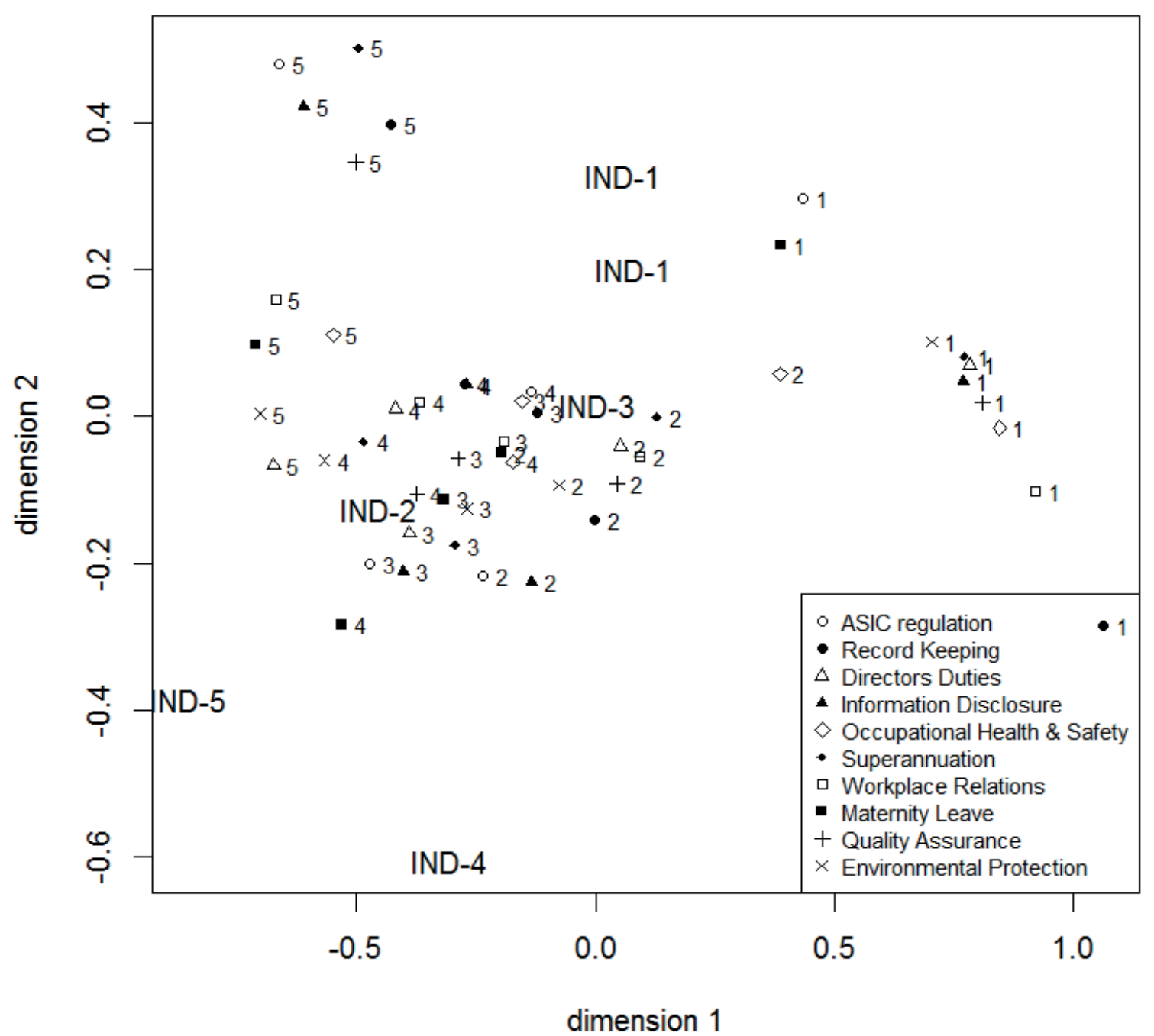

It appears that there is an association between an increase in expenditure on industry advice and an increase in the level of difficulty with various types of regulation. However, the highest level of expenditure, greater than 25 percent, is associated with lower levels of compliance difficulty. This is, perhaps, some evidence that at relatively high levels of expenditure, industry advice can have a considerable impact on easing the difficulty of compliance. However, this suggests that the level of expenditure on industry advice is positively associated with, or may be caused by, the level of compliance difficulty. There seems to be a threshold in compliance difficulty (mostly easy) below which advice from industry is not sought. This implies that if the level of compliance difficulty can be reduced, through policy reform, to below this threshold, then expenditure on industry advice for purposes of regulatory compliance will, in large part, be unnecessary. 
Figure 7 Compliance Difficulty by Lawyer's Advice

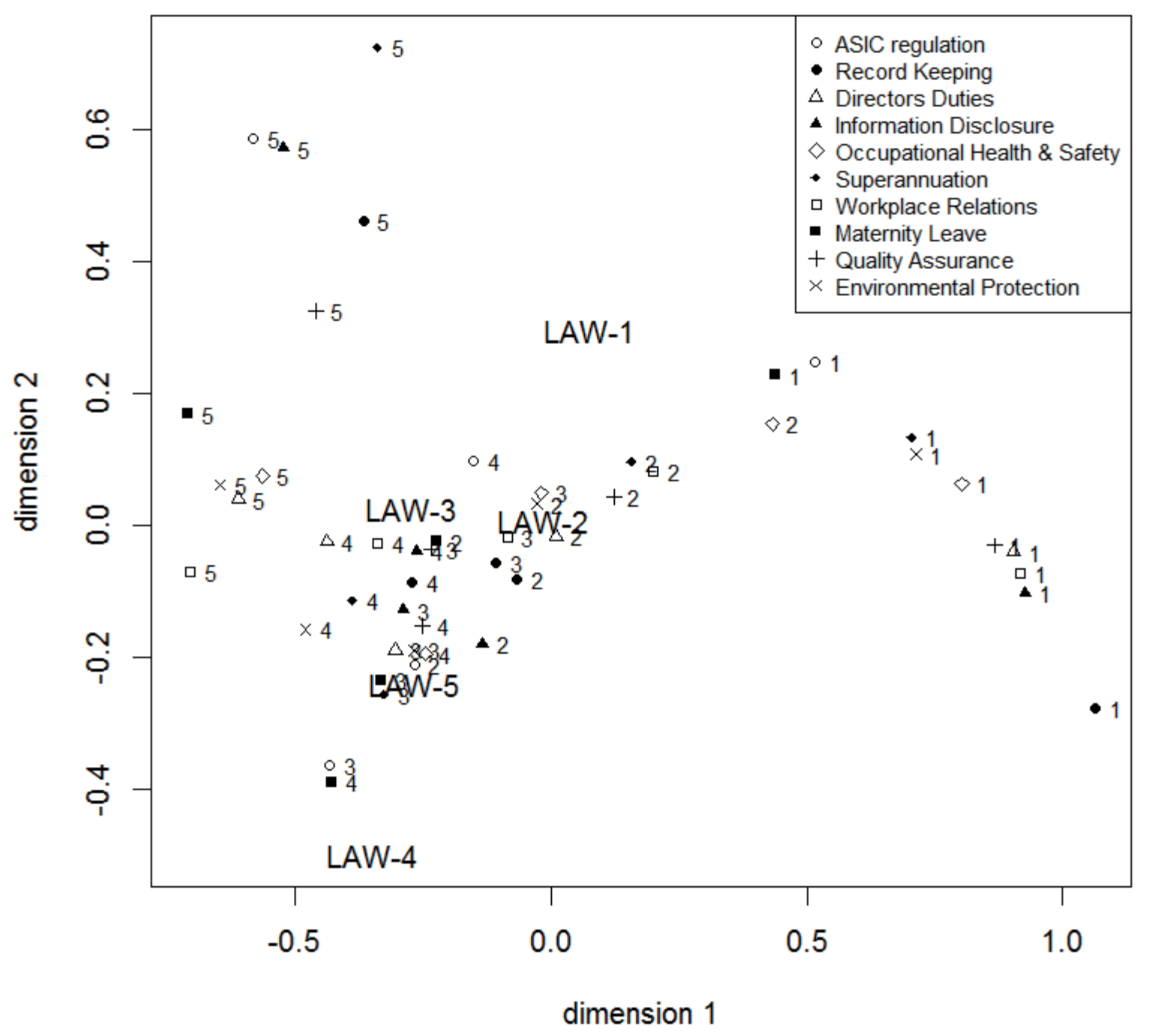

Figure 7 shows the association between the cost of compliance and expenditure on lawyer's advice.

It appears that there is a strong association between an increase in expenditure on advice from lawyers and an increase in the level of difficulty complying with various types of regulation. And the higher levels of expenditure on advice from lawyers may actually be caused by greater difficulty with compliance. Higher levels of expenditure on obtaining advice from lawyers do not appear to have any effect on easing the difficulty with compliance. Again, as with industry advice, there is a very clear threshold in the level of compliance difficulty before advice from lawyers is sought. 
Figure 8 Compliance Difficulty by Accountant's Advice

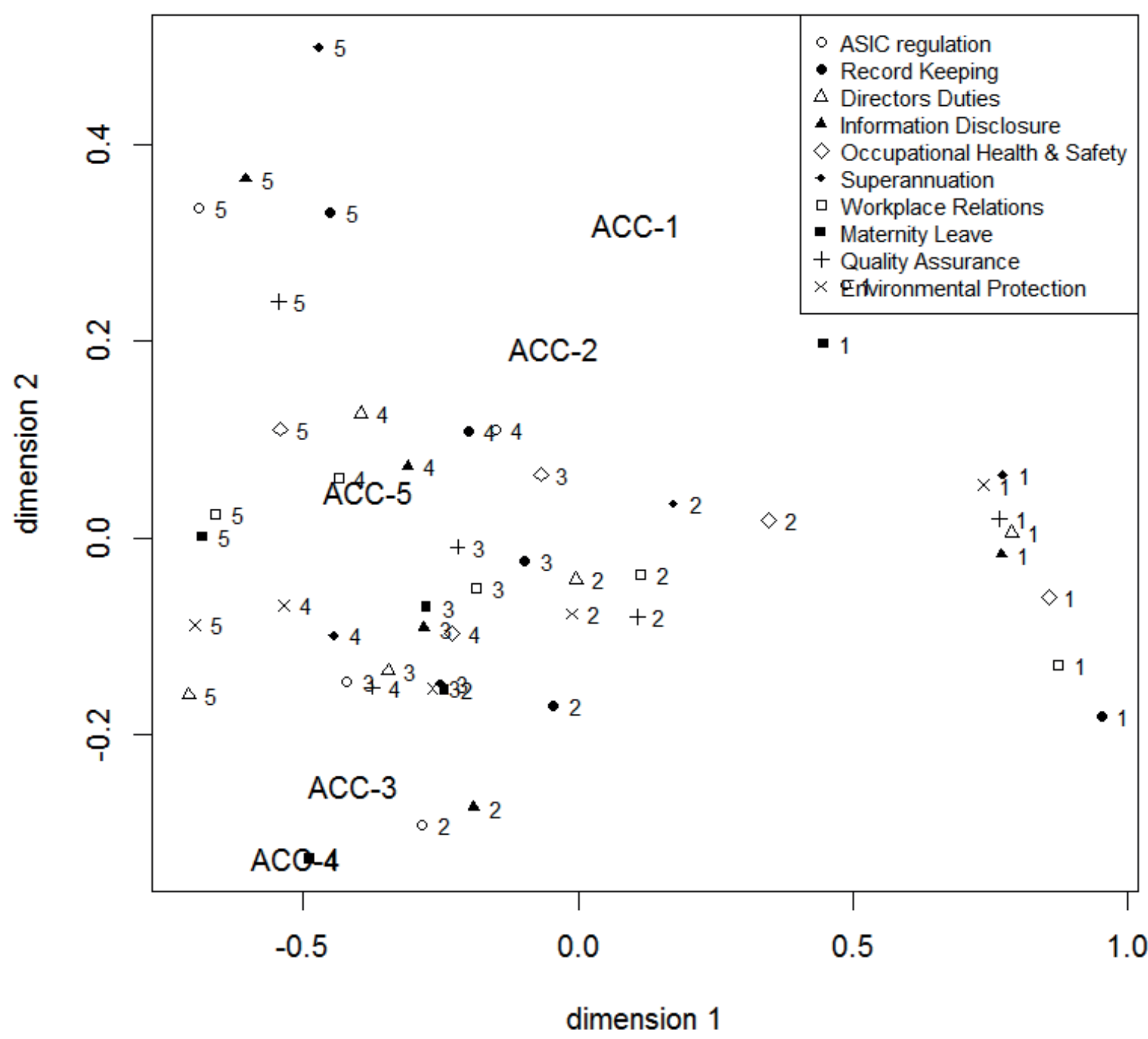

Figure 8 shows the association between the cost of compliance and expenditure on advice from accountants. It appears that there is an association between an increase in the level of difficulty with various types of regulation and an increase with expenditure on advice from accountants. However, at the higher level of expenditure, 20-24 percent and greater than 25 percent, is inversely associated with the level of compliance difficulty. This is perhaps evidence that at higher levels of expenditure, advice from accountants can have a considerable impact easing the difficulty of compliance. It appears accountants are the most useful source of advice for easing the difficulty with compliance compared with any of the other sources of advice considered. There is also evidence, similar to that for the previous sources of advice, i.e. industry and lawyers, of a threshold level of compliance difficulty below which advice from accountants is not sought. 
Figure 9 Compliance Difficulty by Government Advice

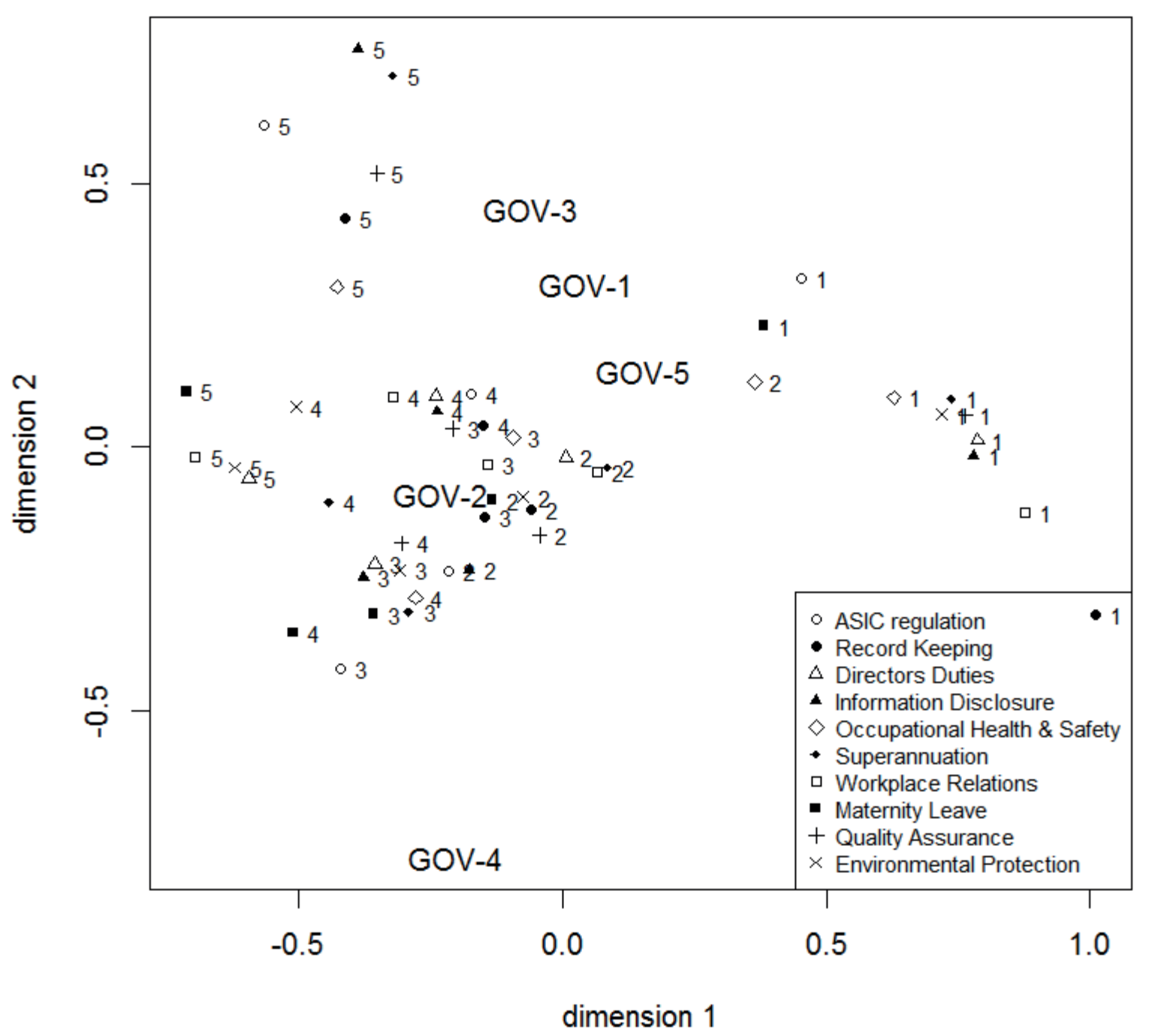

Figure 9 shows the association between the level of compliance difficulty and expenditure on government advice. Unlike any of the previous forms of advice, here, no clear association between the level of compliance difficulty and expenditure on government advice is observed. On the other hand, respondents are quite happy to make comments about the advice they get from government, some of it not complimentary. One respondent regretted

"the lack of support from government agencies e.g. the ATO - in assisting inexperienced business people to comply with their specific piece/s of legislation".

Another commented on a different level of government, lamenting

"the lack of commercial business sense experienced, particularly at local government or field officer status". 
In summary, advice from accountants and industry did shows signs of reducing the difficulty associated with various types of government regulation. For most sources of advice, excluding government, a positive correlation exists between increasing the difficulty with compliance and expenditure on external advice. Moreover, it was also common to see evidence of a threshold level of difficulty before external advice was sought. This implies reducing the level of difficulty complying with various types of government regulation will save businesses considerable expenditure on external advice.

\section{Conclusion}

Clearly, businesses perceive that there are areas of compliance that cause differing levels of difficulty. In an earlier paper the authors (Lewis et al. 2014) found considerable concern among businesses regarding the amount of paperwork involved in keeping compliant and the complexity of the regulations exacerbated by various states and jurisdictions with different rules. These factors, in turn, create other problems, such as the difficulty keeping compliant with government regulation including getting staff to comply with government regulation, maintaining deadlines and understanding the requirements of government regulation. This is not helped by poor quality or overabundance of information which needed to be sifted through to find relevant information. These factors lead to a common charge from business that government over regulates the business sector making compliance costs greater than they need be. Furthermore, there is a common theme regarding additional regulation needed to fulfil the function of government, such as collecting taxes and superannuation payments, without any remuneration for the additional drain on the firm's resources to provide such functions.

This paper has extended the analysis of business perceptions using correspondence analysis to further investigate the links between the characteristics of businesses such as firm size, difficulty with various types of regulation and external advice.

The main findings of this paper are that although there is a positive relationship between firm size and difficulty complying with government regulation, the level of difficulty seems to have a minimum level even for the very small firms. Furthermore it appears that certain types of external advice, particularly advice from accountants, may operate to significantly reduce the difficulty firms have maintaining compliance. Although the use of professional advice can reduce the degree of difficulty of firms in complying with government regulation such advice is still a cost to firms which may unnecessarily detract from firms behaving efficiently and profitably.

\section{References}

Australian Bureau of Statistics (2012), Australian Industry, Cat No 8155.0.

Banks, G. (2006). Rethinking Regulation, Report of the Taskforce on Reducing Regulatory Burdens on Business, available at www.regulationtaskforce.gov.au.

Beldona, S., Morrison, A.M. and O’Leary, J. (2005). Online shopping motivations and pleasure travel products: a correspondence analysis. Tourism Management 26, $561-570$.

Benzecri, J.P. (1992) Correspondence Analysis Handbook. New York: Marcel Dekker.

BERR (2008). The Impact of Regulation on Small Business Performance. Kingston upon Thames: Kingston University.

Berthon, P., Pitt, L., Ewing, M., Ramaseshan, B. and Jayaratna, N. (2001). Positioning in cyberspace: evaluating telecom web sites using correspondence analysis. Journal of Information Systems Management 14, 13 - 21.

Blasius, J. and Thiessen, V. (2001). Methodological artifacts in measures of political efficacy and trust: a multiple correspondence analysis. Political Analysis 9, $1-20$. 
Chittenden, F., Kauser, S. and Poutziouris, P. (2002). Regulatory Burden of Small Business: A Literature Review. University of Manchester, Machester, UK.

Digby, P.G.N. and Kempton, R.A. (1987). Multivariate Analysis of Ecological Communities. London: Chapman and Hall.

Greenacre, M.J. (1984). Theory and Application of Correspondence Analysis. London: Academic Press.

Greenacre, M.J. (1992). Correspondence analysis in medical research. Statistical Methods in Medical Research, 1, 97-117.

Greenacre, M. and Blasius, J. (2006). Multiple Correspondence Analysis and Related Methods. London: Chapman \& Hall.

Greenacre, M.J. and Hastie, T.J. (1987). The geometric interpretation of correspondence analysis. Journal of the American Statistical Association 82, 437 - 447.

Lewis, P., Richardson, A. and Corliss, M (2014). Compliance costs of regulation for small business. Journal of Law and Governance 9, 2 - 24.

Productivity Commission (2007). Performance Benchmarking of Australian Business Regulation. Productivity Commission, Canberra.

R Core Team (2014). R: A language and environment for statistical computing. R Foundation for Statistical Computing, Vienna, Austria. http://www.R-project.org/.

Ter Braak, C.J.F. and Prentice, I.C. (1988). A theory of gradient analysis. Advances in Ecological Research 18, 271-371. 
